Table 1. NUtRIENTS PRESENT IN WhEAT FLOUR (REPRESENTATIVE VALUES)

\begin{tabular}{|l|c|c|}
\hline Nutrients (per 100 gm. flour) & Wholemeal & $\begin{array}{c}\text { Flour of } \\
70 \text { per cent } \\
\text { extraction }\end{array}$ \\
\hline Proteins (gm.) & $12 \cdot 2$ & $11 \cdot 0$ \\
Fat (gm.) & $2 \cdot 3$ & $1 \cdot 1$ \\
Calcium (mgm.) & 45 & 18 \\
Potassium (mgm.) & 376 & 144 \\
Magnesium (mgm.) & 127 & 24 \\
Phosphorus (mgm.) & 287 & 102 \\
Sulphur (mgm.) & 165 & 108 \\
Chlorine (mgm.) & 62 & 53 \\
Tron (mgm.) & $4 \cdot 2$ & $0 \cdot 8$ \\
Copper (mgm.) & $0 \cdot 8$ & $0 \cdot 2$ \\
Manganese (mgm.) & $4 \cdot 5$ & $0 \cdot 4$ \\
Thiamianine ( $\mu$ gmm.) & 910 & 30 \\
Riboflavin ( $\mu \mathrm{gm})$. & 500 & 70 \\
Pyridoxine ( $\mu \mathrm{gm})$. & 100 & 35 \\
Choline (mgm.) & 460 & 220 \\
Folic acid ( $\mu \mathrm{gm})$. & 90 & 50 \\
Biotin ( $\mu$ gm.) & 50 & 12 \\
Nicotinic acid (mgm.) & 8 & $0 \cdot 5$ \\
Pantothenic acid (mgm.) & $7 \cdot 3$ & $1 \cdot 2$ \\
\hline
\end{tabular}

A full set of values is not available for flour of 80 per cent extraction but in general the higher the extraction-rate the greater the retention

there would not appear to be much temptation to add less than the specified quantities of nutrients".

The recommendations of the Conference on the Post-War Loaf, however, were intended to safeguard health by assuring that the flour used for breadmaking contained not only thiamine, nicotinic acid and iron, but also a fair measure of the numerous other nutrients which wheat can supply. Since exact requirements for many of these other nutrients have not yet been established, it cannot be said for certain that the differences between 80 per cent flour and enriched 70 per cent would prove of nutritional significance, but equally it cannot be said that they would not. The matter still awaits investigation (the so-called 70 per cent extraction flour used in the much discussed Widdowson and McCance experiments ${ }^{2}$ contained thiamine, riboflavin and nicotinic acid in quantities greater than is usual at that level and must be assumed to have provided more of the remaining nutrients also). Table 1 sets out some of the nutrients which are present in wheat and shows what a severe reduction occurs in milling to a 70 per cent extraction level. Only a few of these nutrients were given consideration by the Panel, yet the others may be of equal-or even greater-importance.

In this report the Panel gives the warning that "The history of nutrition reveals many instances where the refinement or over-purification of food has led to ill-health and there is no reason to believe that this chapter of knowledge is closed". The Panel, however, seems to assume that the National Food Survey would give adequate warning of any need for further revision of bread policy. But research workers already feel ${ }^{3}$ that over-sophistication of food may provide the explanation of many of the diseases which beset 'civilized' man despite his extensive medical services, and the present time seems inauspicious for a reduction of the dietary supply of some fifteen or more minor nutrients merely to suit trade interests. Moreover, the proposed change would require nearly a quarter of a million extra tons of wheat a year.

M. W. Grant

1 Rep. Conf. Post-War Loaf. (Cmd. 6701.) (London : H.M.S.O., 1945.)

2.Widdowson, E. M., and MeCance, R. A., Med. Res. Counc. Spec. Rep., Ser. 287. (London: H.M.S.O., 1954.)

${ }^{3}$ Platt, B. S., Brit. Med. J., i, 179 (1955). 'Sinclair, H. M., Lancet, i, 381 (1956).

\title{
NATIONAL PHYSICAL LABORATORY
}

\section{OPEN DAY}

$\mathrm{O}^{\mathrm{n}}$ PEN Day' at the National Physical Laboratory, Teddington, serves a dual function: it gives representatives of industry, universities, government departments and the technical and daily Press an insight into the work of one of the largest national research laboratories in Britain and, no less useful, serves to indicate the direction of national research effort in many branches of science and engineering. About three thousand visitors attended this year and 225 exhibits were on view. During the afternoon, the General Board of the Laboratory met to consider the Executive Committee's annual report ${ }^{1}$.

The Metallurgy Division celebrates this year its fiftieth anniversary, and it was appropriate that its exhibits provided evidence of its continued interest in the constitution and structure of metals and alloys in relation to their physical and mechanical properties, work for which the Division has gained an international reputation. An investigation of the constitution of a uranium-palladium system undertaken for the Atomic Energy Research Establishment revealed the interesting feature of a considerable solid solubility of uranium in palladium; since the electronic structure of palladium is known, measurement of certain physical properties such as electrical resistivity, paramagnefic susceptibility, thermoelectric power and lattice parameter suggested that uranium dissolves in dilute solution with an effective valency of 6 , but at higher concentrations the valency is probably 4.

The study of high-purity iron with particular reference to elucidating the embrittling effect of traces of impurities in amounts as low as 0.001 per cent has led to the development of an electrolytic process with the view of producing sulphur-free iron ; a commercial cation exchange membrane was used for dividing the electrolytic cell and preventing the transfer of the sulphur-containing anions. Tensile tests on single crystals of iron at $-196^{\circ} \mathrm{C}$. indicated that orientation had a marked effect on brittle fracture $^{2}$, and further investigations of rolled Swedish iron bar using the National Physical Laboratory X-ray diffractometer confirmed that texture had a marked effect on brittle properties. The tracer laboratory is now in full operation, and equipment has been designed to measure the rate of diffusion of antimony in copper, and to study the self-diffusion of silver under fatigue stress.

The steadily increasing use of radioactive materials has necessitated a simplified calibration procedure for checking their activities. For this purpose and to ease the demand on standard samples of radioactive substances, the National Physical Laboratory's Advisory Committee on Radioactive Standards and 
the Atomic Energy Research Establishment, Harwell, have jointly arranged for the commercial production of a combined beta-gamma ionization chamber for the measurement of $\beta$-ray and $\gamma$-ray sources in the range 1 microcurie to a few millicuries. This equipment was shown in the Physics Division, which also demonstrated the principle of a possible alternative to the fundamental method of determining temperature by the so-called 'gas thermometer'. In this case use was made of the fact that the spontaneous fluctuations in voltage in a metallic conductor, or 'Johnson noise', have a statistical variance which is proportional to the absolute temperature; modern electronie amplifiers have made it possible to measure with the required precision the electrical energy generated, which at the melting point of gold is about a hundred-millionth of a microwatt. Such a method will be useful in permitting the absolute measurement of temperature in circumstances where a gas thermometer could not be used.

Work in the field of high-pressure physics includes the establishment of standards for the measurement of high pressures up to 3,000 atmospheres and beyond. The new National Physical Laboratory 'similarity' method for the precise calibration of pressure balances ${ }^{3}$ was demonstrated and indicated how the hitherto limiting factor of accuracy, namely, the difficulty of measuring the effective area of piston-cylinder assemblies due to distortion, was overcome by using two assemblies of the same dimension but made in materials (hard tool steel and high tensile bronze) having different elastic constants. This Division also showed the results of tests and equipment used for determining the effective biaxial mean stress on fatigue failure, a problem of considerable importance in aircraft design; the biaxial stressing is obtained by applying gas or oil pressure to a hollow test-piece, and the results confirmed that the energy needed to propagate fast fracture is that resident in the compressed gas. Among other interesting exhibits was an ultrasonic viscometer using the National Physical Laboratory split-tube type of barium titanate torsional transducer which, in a high-intensity form, can be made capable of measuring the effects of large particles in hydrosols; and new equipment for investigating thermal and electrical conductivities to well above $1,000^{\circ} \mathrm{C}$.

A notable event in the standards field was the completion in the Electricity Division of a cæsium atomic beam standard of frequency and time interval. The cæsium beam chamber on view incorporated a number of changes suggested by investigations of its performance during the past eight months ${ }^{4}$. The present experimental model provides a unit of time which is accurate to \pm 3 in $10^{10}$ (one-hundredth of a second in one year). By comparison with this primary reference standard, quartz clocks, still the most convenient working standard, can now be calibrated over a period less than one second with a precision of one part in $10^{\circ}$. This improved accuracy in calibration will be made generally available by the $M S F$ standard frequency transmissions which are continuously monitored at the Laboratory.

In the High-Voltage Laboratory of this Division equipment is being set up to investigate the breakdown strength of a wide range of organic liquid dielectrics. It will allow the measurement at atmospheric or reduced pressure, at ambient or higher temperatures, after fractional distillation, fine filtration, drying and degassing, or any combination of these; the effect of the shape and duration of the voltage wave, as well as electrode material, will also be investigated. At the rear of this building a new million-volt $700-\mathrm{kVA}$. oil-immersed transformer is being installed to replace the bank of air-insulated transformers which have given useful service over the past thirty years. Supporting towers and rainspray equipment will also be provided for outdoor power-frequency tests.

A number of exhibits indicated the valuable assistance that the Divisions can give to each other in the course of their work. A good example is the new techniques used by the Metrology Division in the preparation of fused quartz cylinders for the construction in the Electricity Division of a new primary standard of inductance, from which the $\mathrm{ohm}$ is derived. With the aid of special lapping blocks, the variations in effective diameter of the helix have been reduced from $15 \mu$ to $5 \mu$.

The Metrology Division also showed, in its final form, a microwave interferometer, the only equipment of its kind in existence, for the precise determination of the free-space vacuum velocity of electromagnetic waves. The fairly recent introduction of the geodimeter, which uses the speed of light for measuring distances of the order of $10 \mathrm{~km}$., emphasizes the need for a value accurate to at least one part in a million. This interferometer uses two opposing microwave transmitters fed from a common source and, between them, a movable carriage supporting two receiving apertures, each facing a transmitter. The received signals are mixed to produce interference, and an accurately measured bar, two metres long, is used for determining the displacement corresponding to about 1,000 half-waves with great precision; the operating frequency is high $(72 \mathrm{kMc} / \mathrm{s}$.$) , and is measured by comparison$ with high harmonics of a quartz-crystal frequency standard.

The close contact which this Division maintains with industry was evident in the two methods demonstrated for measuring the camber of large rolls, one using an autocollimator and the other an interferometric technique. A number of exhibits, demonstrating the application of pneumatic gauging, were of special interest. The thickness of thin sheet material was shown being measured continuously by this method as it passed over a roller beneath a number of air jets. This apparatus, as at present designed, will measure to a lower thickness limit of 0.002 in. and an accuracy of \pm 1 per cent. By means of a selector switch, variation in thickness of the sheet beneath any one of the jets can be continuously plotted by a pen recorder. A similar technique was demonstrated for testing the flatness of unexposed photographic plates.

Two thin-film type bolometers are being developed in the Light Division to meet the industrial need for sensitive non-selective detectors of infra-red radiation. Thin films of gold or antimony, less than twomillionths of an inch thick, supported on a plastic pellicle, are used. The blackened gold film bolometer is quite as effective as the best thermal detectors at present available and is robust enough for monochromators used in chemical process control; the amorphous antimony bolometer also shows promise in that it is highly sensitive to voltage and has an impedance so large that it can be connected directly to a valve amplifier, thus saving the expense of a step-up transformer.

Among other interesting exhibits in this Division were a photo-electric polarimeter which was con- 
structed to investigate inaccuracies in the calibration of quartz plates used as standards of optical rotation; and a gas refractometer developed for testing trichloroethylene inhalers, with which the concentration of trichloroethylene in air is determined by comparing the refractive index of the vapour mixture with that of air in a Jamin-type interferometer. New methods have been developed for producing replica diffraction gratings in plastic ; they make it possible to join several longths to form continuous accurate gratings several feet in length. It was shown how these gratings can be used for the accurate measurement of movement or displacement by counting the moiré fringes produced when a short index grating is moved over a length of fixed grating of the same pitch. The possibilities of this technique of indicating position is being actively investigated and has been adopted in one instance for the automatic control of machine tools.

Work on the design of electronic digital computers continues in the Control Mechanisms and Electronics Division, which exhibited units of the new Automatic Computing Engine (ACE), that was seen in the process of construction. This will be a more powerful tool than its predecessors, the ACE Pilot Model and its engineered version DEUCE, as made by the English Electric Co., Ltd. The new computer will have a larger storage capacity or 'memory' and have an overall speed four times greater than DEUCE; in a typical working day it will average 20,000 ' $t$ hr se address' operations per second and its mercury delis. lines and magnetic drums will store a total of $1 \frac{1}{2}$ million binary digits. With its other special facilities this machine will allow the solution of very complex problems which have hitherto not been possible with existing computers. A simplified flow diagram for wage accounting directed attention to the possible use of a high-speed computer, with magnetic tape equipment, in office work. This was based on the work done for a study group formed in 1954, consisting of representatives of the Organization and Methods Division of the Treasury, the Ministry of Pensions and National Insurance and the National Physical Laboratory, the first report of which has just been published ${ }^{5}$. This Division is also concentrating on the design of data-processing equipment and exhibited an automatic graph-plotter which enables information in punched card form to be plotted automatically at a rate of one point every two seconds for points lying fairly close together. Information is read from the cards serially and supplied through a relay distributor to the relay stores, the outputs of which are voltages proportional to the number held; these voltages are then supplied to the plotting table, which traverses the carriage to the corresponding point, and the plotting head is operated.

The Mathematics Division is now using DEUCE for solving large-scale numerical calculations arising in scientific research and industrial design. This machine was seen in operation and is being used for solving problems in mathematical physics, linea. algebra, ballistics and aircraft flutter.

The facilities of the Ship Division are being extended, and a model was shown of the new Ship Hydrodynamics Laboratory now being built at Feltham, Middlesex. This will provide a ship modeltesting tank $1,300 \mathrm{ft}$. in length, $45 \mathrm{ft}$. wide and $25 \mathrm{ft}$. deep, and its carriage will have a maximum speed of $50 \mathrm{ft}$. per sec. There will also be a new water tunnel 40 in. in diameter for research on propellers; work on 'cavitation' will be facilitated by a resorber circuit which will go $200 \mathrm{ft}$. below ground-level. A problem associated with the arrangement for supporting and driving the propeller model in this new water tunnel was demonstrated. A mechanical model indicated the method of investigating the different modes of whirling of an overhung shaft and the effects of alteration in the shafting or bearings at critical whirling speeds, with the view of determining the best supporting system. In the Yarrow Tank a lightship was seen undergoing tests in rough water. These experiments are on behalf of the Corporation of Trinity House and the Commissioners of the Port of Calcutta, and are being made under conditions simulating the effect of tide, wind and waves on the riding behaviour of an anchored lightship. 'The high rable tensions are affected by the hull form, and methods of reducing the cable tension have been suggested.

Of special interest to visitors to the Aerodynamics Division were the wind tunnel exhibits demonstrating methods for improving the efficiency of lifting surfaces by preventing flow separation. Such studies are of vital importance for improving the landing and take-off performance of high-speed civil and military aircraft, where the trend towards highly swept wingforms has necessitated relatively high landing and take-off speeds. High lift was demonstrated in the $13 \mathrm{ft} . \times 9 \mathrm{ft}$. wind tunnel by blowing high-velocity air over a trailing-edge flap of a half-model delta wing to re-energize the boundary layer. In the $9 \mathrm{ft}$. $\times 7 \mathrm{ft}$. wind tunnel experiments were in progress to ascertain the usefulness of boundary-layer control at the wing nose when combined with jet flaps at the wing trailing-edge.

In high-speed flight, shock-induced boundary layer separation from a wing or other component of an aircraft seriously affects suability and control of the aircraft. This formed the subject of a film, in colour, which was shown to visitors. An interesting exhibit concerned experiments on a thin half-aerofoil section designed to be free from boundary-layer separation for an appreciable range of lift coefficients at all speeds, thus enabling the formation of a shock wave to be studied independently of boundary-layer interaction and a check to be made on theoretical results. The influence of the shape of the leading edge on change in the type of separation that occurs as the Mach number is raised for a wing at high incidence was also being studied.

Equipment specially designed for the measurement of aerodynamic forces on oscillating wings was exhibited in this Division. It is intended to provide fundamental data relating to oscillating forces at high speeds and frequencies, and will be used for checking the theoretical methods at present used when designing aircraft to guard against oscillatory instability in flight. An electro-mechanical feed-back system is used, incorporating a torsion bar linking two inertias, one carrying the model and a displacement pickup, and the other being electromagnetically excited at its natural frequency.

The Laboratory's testing facilities are constantly being extended to meet new demands. Three new water-baths have been installed in the Test House to facilitate testing and avoid fatigue of observers testing clinical thermometers, of which more than half a million were tested last year. With the increasing use of viscometers in various industrial applications, and by the oil industry in particular, there has been an increasing demand for the calibration of a range and variety of these instruments ; 
temperature control has been installed in rooms used for this work. The testing of trichloroethylene inhalers intended for use by registered midwives has been facilitated by the use of the new gas refractometer referred to previously. Two prototypes have been approved, and about 110 inhalers have been tested. 'Trouble-shooting', the theme of an interesting exhibit, stressed the assistance given by the Test House to enable manufacturers to overcome their production difficulties and to improve the quality and accuracy of their output.

E. I. Brimelow

1 National Physical Laboratory. Report for the Xear 1955 (London: H.M.S.O., 1956)

${ }^{2}$ Allen, N. P., Hopkins, B. E., and McLennan, J. E., Proc. Roy. Soc. A, 234, 221 (1956)

${ }^{3}$ Dadson, R. S., Nature, 176, 188 (1955).

4 Essen, L., and Parry, J. V. L., Nature, 177, 744 (1956).

5 "Wage Accounting by Electronic Computer" (London: H.M.S.O., 1956).

\section{OBITUARIES}

\section{Prof. Carl Ramsauer}

Carl Ramsauer, who died in Berlin on December 24, 1955, was an outstanding character as well as an outstanding physicist. As a young man, he made his way by his toughness and purpose. Born on February 6, 1879, in Osterburg, a little place in Oldenburg where his father was the Lutheran parson, in his early twenties he occupied a diversity of positions, including those of schoolmaster and assistant in the torpedo laboratory at $\mathrm{Kiel}$, at which University he took his doctorate with an interesting and original thesis on the mechanism of ricochet from water. He was twenty-eight when Lenard, who had been professor at Kiel, enabled him to take up an academic career by appointing him to a post in the Physics Institute at Heidelberg. Here he worked, except for the war period, during which he was an artillery officer, until 1921, when he was appointed professor of physics at the Technische Hochschule at Danzig. With Lenard he carried out a series of significant researches on the ionization produced by ultra-violet light; but the work that brought his name into prominence was his discovery, in 1921, that slow electrons pass much more easily than swifter ones through the atoms of the rare gases, the so-called Ramsauer effect. In this connexion he introduced the term Wirkungsquerschnitt (effective cross-section), which has been so widely used.

At Danzig, Ramsauer proceeded to transform the small and comparatively unimportant department into a first-class institute for teaching and research in physics. He was by inclination and training an outstanding teacher, taking the greatest pains and pleasure to devise effective lecture experiments and to make clear the fundamentals of the subject. The research school, which was occupied mainly, but by no means exclusively, with the passage of electrons through matter, was known for the precision and clarity of its work. By 1928 his reputation was such that when the Allgemeine Elektricitätsgesellschaft decided to found a research institute, Ramsauer was appointed to direct it. His gifts as an organizer and controller of research found full expression in this extremely responsible post. Under him work proceeded not only in physical, but also in chemical, electrotechnical, metallurgical and other departments of the great institute. He installed 'technicalphysical workshops', which were of great value. $\mathrm{He}$ continued his personal research on effective atomic and molecular cross-sections, and the work which he carried out with Kollath on the scattering of protons is classical. In 1931 he became joint editor of the Zeitschrift für technische Physik, and many other responsibilities of this nature accrued to him.

During the Second World War, Ramsauer was elected president of the Deutsche Physikalische
Gesellschaft, a very difficult position at that time. With characteristic courage he spoke out against the many abuses and shameful personalities which were ruining German physics, his letter, sent in 1942, to Rust, then Minister for Education, being particularly uncompromising. It had no result ; but if Ramsauer had been a less valuable and less respected man it might have been fatal for him.

After the War, Ramsauer occupied himself with reorganizing the teaching of physics at the Technische Hochschule at Charlottenburg, a task for which his gifts and experience particularly fitted him. In 1953 he published a remarkable little book dealing with the history of certain fundamental experiments in physics. He did not give up his post until he reached the age of seventy-five, and died shortly after his resignation.

Ramsauer was a quite exceptional personality. $\mathrm{He}$ disliked any parade of sentiment, but he was a staunch friend and a man of firm principles, who never truckled to those in power. He was a most entertaining talker, with a strong and sometimes biting sense of humour, to which he gave epigrammatic expression. For example, of a certain somewhat undistinguished physicist who had a double name-let us call him Wolf-Braun-he said, "GaussWeber were two men, Mittag-Leffler was one man, Wolf-Braun was nobody". He had a close acquaintance with German university folk-lore, including the legends of Bonifacius Kiesewetter, and a great knowledge of German literature in general, including many byways. He will long be remembered by all who had to do with him, and especially by the few still living who knew him at Heidelberg.

$$
\text { E. N. Da C. Andrade }
$$

\section{Sir John Stirling-Maxwell, Bart., K.T.}

Sir John Stirling-Maxwell died on May 30 at the age of eighty-nine at his home, Pollok House, famous for its lovely gardens, near Glasgow. He succeeded his father at the age of eleven, and went to Eton and then on to Trinity College, Cambridge. He was Conservative member of Parliament for the College Division of Glasgow between 1895 and 1906, when he lost the seat. It was then that he gave his time to his real hobby. Sir John may be termed one of the early modern pioneers of forestry, then called arboriculture in Scotland and England, in the latter part of the past century and the early years of the present. He studied the subject intensively in many European countries and made use of the knowledge so acquired on his own estate, and was always ready with advice or suggestions to friends.

In his own practice, after failures to establish sitka spruce plantations on his estate at Corrour, and his 